\title{
NEWS-BASED SOFT INFORMATION AS A CORPORATE COMPETITIVE ADVANTAGE
}

\author{
Ming-Fu HSU ${ }^{1}$, Te-Min CHANG ${ }^{2}$, Sin-Jin $\mathrm{LIN}^{3 *}$ \\ ${ }^{1}$ English Program of Global Business, Chinese Culture University, Taipei, Taiwan \\ ${ }^{2}$ Department of Information Management, National Sun Yat-sen University, Kaohsiung, Taiwan \\ ${ }^{3}$ Department of Accounting, Chinese Culture University, Taipei, Taiwan
}

Received 26 August 2018; accepted 17 August 2019

\begin{abstract}
This study establishes a decision-making conceptual architecture that evaluates decision making units (DMUs) from numerous aspects. The architecture combines financial indicators together with a variety of data envelopment analysis (DEA) specifications to encapsulate more information to give a complete picture of a corporate's operation. To make outcomes more accessible to non-specialists, multidimensional scaling (MDS) was performed to visualize the data. Most previous studies on forecasting model construction have relied heavily on hard information, with quite a few works taking into consideration soft information, which contains much denser and more diverse messages than hard information. To overcome this challenge, we consider two different types of soft information: supply chain influential indicator (SCI) and sentimental indicator (STI). SCI is computed by joint utilization of text mining (TM) and social network analysis (SNA), with TM identifying the corporate's SC relationships from news articles and SNA to determining their impact on the network. STI is extracted from an accounting narrative so as to comprehensively illustrate the relationships between pervious and future performances. The analyzed outcomes are then fed into an artificial intelligence (AI)-based technique to construct the forecasting model. The introduced model, examined by real cases, is a promising alternative for performance forecasting.
\end{abstract}

Keywords: supply chain network, sentimental indicator, decision making, data envelopment analysis.

JEL Classification: C45, C67, M15, M41.

\section{Introduction}

Domestic corporates in most industries face extreme risk and operate in a highly volatile business world due to globalization and international trade. Compared to multinationals and global enterprises, domestic corporates usually lack sufficient human capital, financial resources, and risk-absorbing capability, as well as are unable to quickly react to customer requirements, which could lead to higher risk exposure and tremendous uncertainty. Supply

${ }^{*}$ Corresponding author. E-mail: annman1204@gmail.com

This is an Open Access article distributed under the terms of the Creative Commons Attribution License (http://creativecommons. org/licenses/by/4.0/), which permits unrestricted use, distribution, and reproduction in any medium, provided the original author and source are credited. 
chain (SC) collaboration, which is an architecture for arranging interdependencies among operations, process/product designs, and sales forecasting/planning in order to come up with consensus strategic decisions among SC partners, has been widely deemed as an efficient and useful method for addressing the challenge of globalization and upgrading a nation's industrial level (Tan, Lyman, \& Wisner, 2002; Wu \& Chiu, 2018; Hu, Jianguo, \& Tzeng, 2018). The rationale is that corporates highly involved in SC collaboration can facilitate knowledge sharing, create customer loyalty and value, shorten product waiting time, and increase profitability by utilizing the intertwined and interconnected network for the spread or exchange of dissimilar types of information among SC partners, including operational and tactical strategies, scarce resources, and opportunities (Narasimhan \& Nair, 2005; Kim, 2014; Bhattacharjee \& Cruz, 2015).

Grounded on the concept of linear value chain introduced by Porter, a SC is an architecture consisting of raw material providers, manufacturers, transporters, and customers linked together via a feed forward flow of materials and feedback flow of information (Kim, Choi, \& Yan, 2011; Eskandarpour, Dejax, Miemczyk, \& Péton, 2015). Unfortunately, today's SC in essence is not a simple linear structure (i.e., one-to-one), but rather a sophisticated network structure made up of numerous business types (Lambert, Cooper, \& Pagh, 1998) - that is, the traditional linear relationships among SC partners are substituted by complicated and network-based relationships. Due to the opaque nature of SC relationships, it is nearly impossible to recognize all of them among SC partners in a network. Thus, how to accurately identify a corporate's relationships among its SC partners turns out to be much more critical in academia and practice.

Identifying a corporate's SC relationships via interviews and questionnaires is a much more precise process, but its dramatic weaknesses include that it is time-consuming and entails considerable financial costs and human resources. To solve these critical problems, this study proposes a systematic and efficient avenue to identify a corporate's inherent SC relationships. Based on prior work done by Bao, Li, Yu, and Cao (2008), we can infer that the corporates showing in the same news may probably have some business relationships (i.e., suppliers, competitors, or rivals) among them. In order to make the result more accurate, we further establish a domain-specific word list to refine a corporate's SC relationship. Therefore, this study performs text mining (TM) with a domain-specific word list to extract a corporate's SC relationship from news articles. Compared to previous studies, the proposed avenue is more systematic and efficient as well as involves a lot less human labor in the equation.

Corporates that exhibit higher involvement in SC relationships are widely acknowledged to have an essential competitive edge in today's knowledge-based economy, because stronger SC relationships can help them to facilitate knowledge sharing, have quick access to scarce resources, increase their profit margin, reduce lead times, and speed up reactions to consumers' requirements. Thus, how to evaluate a corporate's impact on its SC relationship network has become an active research topic. To deal with this task, we conduct social network analysis (SNA), which investigates social structures via network structure and graph theory. However, even if numerous academic reports conclude that the relationship between financial performance and its involvement in a SC network is positive, there is no conclusive decision so far (Beamon, 1999; Kwon \& Suh, 2005). The reasons for not obtaining a conclu- 
sive decision may come from traditional performance measures focused on accounting ratio analysis (such as, ROA: return on assets and ROE: return on equity) that are too simplify, which cannot represent the whole picture of a corporate's conditions in today's highly volatile and aggressive business atmosphere. To make an overarching and robust judgment, this study prefers to approach it from the data envelopment analysis (DEA) perspective (Cinca \& Molinero, 2004; Chen \& Zhu, 2011; Lin \& Hsu, 2018). The merits of DEA can be briefly summarized as follows: (1) it can handle the evaluation task by considering multiple inputs and outputs in the same time without a priori assumption (i.e., profit maximization or cost minimization); and (2) it can provide a complete and intuitive performance score for decision makers to make a judgment. However, the performance score calculated by DEA is influenced by the inclusion or exclusion of an input or an output (Parkin \& Hollingsworth, 1997; Sagarra, Mar-Molinero, \& Agasisti, 2017; Scalzer, Rodrigues, Macedo, \& Wanke, 2018) - that is, the utilization of different inputs or outputs leads to different performance scores. Rather than employ a single DEA specification, this study chooses to go beyond a single performance score and extends to multiple DEA specifications (i.e., this study considers all the existing combination strategies). To make the outcome more realizable to non-specialists, multidimensional scaling (MDS) (one type of dimensionality reduction techniques) is conducted to visualize the essential elements of the data. Through joint utilization of multiple DEA specifications and MDS, the decision makers can appropriately discriminate the difference between superior and inferior operating performances.

Petersen (2004) stated that information can typically be divided into two different types: hard information and soft information. The former refers to numerical information, including stock prices and trading volumes, while the latter refers to textual information, such as sentiment/opinions and ideas. Most previous research studies related to financial risk forecasting rely heavily on hard information (i.e., numerical ratios), especially in financial crisis prediction and credit risk prediction. However, Beattie, Mcinnes, and Fearnley (2004) indicated that numerical information comprises only $20 \%$ of all information. Merely utilizing numerical information to reach a final conclusion is not trustful and robust. Hajek, Olej, and Myskova (2014) also noted that forecasting models with only numerical ratios are not yet fully capable of explaining the relationships between previous and future financial performances. One possible reason may be from omitting essential soft information (i.e., textual information) that can be substantially extracted from text documents (Gajzler, 2010). Grounded on the work done by Huang, Zang, and Zheng (2014), they indicated that the textual information can yield incremental messages beyond a quantitative ratio by providing well-organized descriptions to clarify company's numerous aspects. Loughran and McDonald (2011) also indicated that the sentiment from documents significantly correlates to a corporate's profit potential, share turnover, and earnings surprise. However, far too little works focus on establishing performance forecasting model by utilizing sentimental indicators. Improper performance forecasting could lead to an inability to recognize an unhealthy company before a financial crisis is triggered.

To fill this vacancy in the literature, we extract the sentiment indicators from the most important section of annual reports, called management discussion and analysis (MD\&A), and use it to construct our operating performance forecasting model. The reasons for choos- 
ing MD\&A are as follows: it (1) provides a narrative disclosure of a corporate's financial statement that enhances interpretability by market participants; it (2) covers the full financial disclosure report and determines the context within which information should be further inspected; and and it (3) gives information about the variability of a corporate's earnings and cash flow (Li, 2010; Tajvidi, \& Karami, 2017). Through joint utilization of hard information and soft information, we are able to achieve a much more precise and unbiased forecasted outcome. West, Dellana, and Qian (2005) also indicated that even a little improvement in forecasting performance can result in saving a considerable amount of money to corporates and market participants.

The objectives of this study are summarized as follows.

- The study proposes a novel decision-making architecture to forecast operating performance, which has been widely deemed as the prior stage before financial troubles.

- To describe the whole picture of a corporate's operations, this study goes beyond the traditional one-input and one-output accounting ratios and further extends to a multiple-input and multiple-output assessment measure (i.e., DEA).

- To yield more comprehensive information for decision makers to form their own judgments, this study extends the singular DEA specification to multiple DEA specifications (i.e., it considers all the combination strategies).

- To make the outcome more assessable to decision makers, we conduct MDS (one type of dimensionality reduction techniques) to visualize and represent the main characteristics of the data.

- To identify a corporate's SC relationships, we perform TM with a domain-specific word list to analyze the news articles and then establish its SC network.

- To evaluate the strength of a corporate's involvement in a SC network, we conduct SNA.

- To improve the model's forecasting quality, we take soft information (i.e., sentimental) into consideration.

The remaining of this study is structured as follows. Section 1 presents the methodologies used. Section 2 describes the experimental results. The final section provides and discusses experimental results.

\section{Methodologies}

\subsection{Data envelopment analysis: DEA}

Charnes, Cooper, and Rhodes (1978) introduced data envelopment analysis (DEA) in 1978 which is a popular mathematical programming method based on the frontier theory for evaluating the relative efficiencies of multiple inputs and outputs of decision-making units (DMUs). If the efficiency score is less than 1, a DMU is considered relatively inefficient (Lu, Liu, Kweh, \& Wang, 2016; Lu, Kweh, Nourani, \& Huang, 2016; Çalik, Yapici Pehlivan, \& Kahraman, 2018; Radojicic, Savic, \& Jeremic, 2018; Joulaei, Mirbolouki, \& BagherzadehValami, 2019). By executing DEA, we are able to understand how efficient a unit is relative to its competition and see the relative shortages of inefficient units (Ross \& Droge, 2002). Thus, 
this study applies DEA to determine corporate operating performance and briefly illustrates it as follows (Kritikos, 2017; Zheng, Wang, Chen, \& Zhang, 2019; Nosrat, Sanei, Payan, Hosseinzadeh, \& Razavyan, 2019).

Assume that there is a group of $b$ DMUs to be measured, where each DMU has $h$ inputs and $k$ outputs. We present utilizing the conventional denotations in DEA by $x_{i j}=(i=1, \ldots, h)$ and $y_{r j}=(r=1, \ldots, s)$, which are the values of inputs and outputs of $D M U_{j}(j=1, \ldots, n)$, and which are known and positive. The mathematical formulation of the well-known DEA-CCR model is represented in Eq. (1) and can be used to assess the relative efficiencies of each DMU:

$$
\begin{aligned}
& \operatorname{Max} \vartheta_{0}=\frac{\sum_{r=1}^{k} m_{r} y_{r o}}{\sum_{i=1}^{h} s_{i} x_{i o}} \\
& \text { subject to } \\
& \vartheta_{j}=\frac{\sum_{r=1}^{k} m_{r} y_{r j}}{\sum_{i=1}^{h} s_{i} x_{i j}} \leq 1, \quad j=1, \ldots, b, \\
& m_{r} \geq 0, \quad s_{i} \geq 0, \quad r=1, \ldots, k . \quad i=1, \ldots, h .
\end{aligned}
$$

Here, $D M U_{o}$ expresses the DMU under measurement, and the $m_{r}$ and $s_{i}$ are represented as the weights assigned to the outputs and inputs, respectively. If there is a group of positive weights in which $\vartheta_{0}^{*}$ reaches 1 , then $D M U_{o}$ is relatively efficient (that is, $D M U_{o}$ is lied on the efficient frontier); otherwise, it is relatively inefficient (that is, $D M U_{o}$ is not lied on the efficient frontier).

By implementing mathematical transformation strategy (Charnes \& Cooper, 1962), the aforementioned task can be switched into a linear programming task.

$$
\begin{aligned}
& \operatorname{Max} \vartheta_{o}^{*}=\sum_{r=1}^{k} m_{r} y_{r o} \\
& \text { subject to } \\
& \sum_{r=1}^{k} m_{r} y_{r j}-\sum_{i=1}^{h} s_{i} x_{i j} \leq 0, \quad j=1, \ldots, b, \\
& \sum_{i=1}^{h} s_{i} x_{i o}=1, \\
& m_{r} \geq 0, \quad s_{i} \geq 0, \quad r=1, \ldots, k . \quad i=1, \ldots, h .
\end{aligned}
$$

The above DEA-CCR model provides an efficiency score for each DMU, making it tell the difference between efficient and inefficient DMUs. By assigning weights to each DMU's inputs and outputs and maximizing the ratio of the weighted sum of outputs to the weighted sum of inputs, we can obtain the DMU's relative efficiency score. DEA-CCR models consists of two different types: input-oriented and output-oriented. An output-oriented one is selected, because a company generally try to use the resource at hand to reach the fulfillment of the company's goal.

\subsection{Random vector functional link networks: RVFL}

With its advantage of universal approximation capability, the artificial neural network (ANN) with a back-propagation (BP) supervised learning mechanism is one of the most popular machine learning algorithms, but it has some weaknesses, such as slow convergence and being 
extremely sensitive to learning rate determination and difficulty at escaping from the local minimum (Schmidt, Kraaijveld, \& Duin, 1992; Forero, Cano, \& Giannakis, 2010; Scardapane, Comminiello, Scarpiniti, \& Uncini, 2016). To handle these challenges, a randomized-based $\mathrm{NN}$, called the random vector functional-link (RVFL) network, was introduced that assigns a weight randomly and connects the input and output layers by a functional link (Pao \& Takefuji, 1992; Friedman, Hastie, \& Tibshirani, 2009; Georgopoulos \& Hasler, 2014). Igelnik and Pao (1995) and Georgopoulos and Hasler (2014) indicated that randomly generating the weights from the input layers to the hidden layers can enhance the model's forecasting performance.

Assume that the approximation of $g(x)$ is represented as $g^{*}(x)$ and can be used to map input data $\mathbf{x}=\left[x_{1}, x_{2}, \ldots, x_{n}\right]$ to a target value $Y=\left[y_{1}, y_{2}, \ldots, y_{n}\right]$. We present a mathematical representation of RVFL as:

$$
g^{*}(x)=\sum_{j}\left(\alpha_{j} \cdot \mathrm{b}\left(\mathrm{F}_{j}^{T} \mathbf{x}+g_{j}\right)\right)
$$

where $F_{j}$ is the vector of weights connecting the input to the $j^{\text {th }}$ enhancement node, and the error term and the weights connected to the output are $g_{j}$ and $\alpha_{j}$, respectively. Since the weights from the input layer to enhancement node and error term can be randomly determined in an appropriate range and kept constant in the learning procedure, the only computation task is to determine the output weight $\alpha$, which can be realized via handling the following task:

$$
Y_{i}=e_{i}^{T} \alpha, \quad i=1,2, \ldots, N,
$$

where $N$ denotes the total amount of research targets, and $e$ expresses the vectors that can be used to concatenate initial and random features.

In order to avoid the problem of over-fitting, we conduct the Moore-Penrose Pseudoinverse. Zhang and Suganthan (2016) further indicated that the ridge regression can perform a satisfactory job in handing this task. Thus, we apply ridge regression to handle the following task:

$$
\sum_{i}\left(\mathrm{Y}_{i}-\mathrm{e}_{i}^{T} \alpha\right)^{2}+\beta\|\alpha\|^{2},
$$

where $\alpha=E\left(E^{T} E+\beta I\right)^{-1} Y$ denotes the solution of the aforementioned task, $\beta$ depicts the regularization value, and the input and output matrices are $E$ and $Y$, respectively. For a more detailed illustration of RVFL, one may refer to Zhang and Suganthan (2016), Scardapane, Wang, Panella, and Uncini (2015), and Katuwal, Suganthan, and Zhang (2018).

\section{Research architecture and experimental outcomes}

\subsection{The research target and dependent variable}

Taiwan, a small, resource-scarce, densely-populated island nation, has gained considerable attention due to its great influence on the global supply chain, especially in high-technology electronics products. Above 50\% of the world's personal computers (PCs) are either made in Taiwan or contain an essential electronic components provided by a Taiwanese company 
(Wu \& Chiu, 2018). Moreover, the electronics manufacturing industry in Taiwan has received numerous government grants and beneficial financing incentives, turning it into a mainstream of local economy as well as an important funding source to worldwide market participants. However, because manufacturing firms have shorter product lifecycles, greater revenue volatility, and higher customer turnover rates, there is an imperative need to establish a sophisticated mechanism for decision makers to realize the current status of corporate operations. Thus, we choose the top 1000 manufacturing companies in Taiwan as our focused sample. All the company-level data were collected from Taiwan Economic Journal (TEJ) database for the period 2015-2017.

How to appropriately describe the whole picture of a corporate's operating situation is an important task. This study prefers to go beyond a single DEA score and extends to multiple DEA specifications. By implementing a bundle of performance scores (i.e., multiple DEA specifications), we can reach a more comprehensive and robust outcome. The used variables (i.e., inputs and outputs measures) should be decided before constructing the multiple DEA specifications. Total liability (TL) and total equity (TE) are designated as input variables, and profit ratio (PR), ROA, and ROE are designated as output variables (Wang, Lu, Kweh, \& Cheng, 2014; Hsu, 2019a, 2019b; Lin, Chang, \& Hsu, 2019). We conduct the Pearson correlation to test the representativeness of the chosen variables. The result in Table 1 states that all the chosen variables show significant positive correlation - that is, no selected variable should be omitted.

Table 1. The Pearson correlation result

\begin{tabular}{|c|c|c|c|c|c|}
\hline & TL & TE & PR & ROA & ROE \\
\hline TL & 1 & & & & \\
\hline TE & $0.825^{\star *}$ & 1 & & & \\
\hline PR & $0.623^{\star *}$ & $0.713^{* *}$ & 1 & & \\
\hline ROA & $0.702^{\star *}$ & $0.651^{\star *}$ & $0.866^{* *}$ & 1 & \\
\hline ROE & $0.877^{* *}$ & $0.712^{* *}$ & $0.579^{* *}$ & $0.842^{* *}$ & 1 \\
\hline
\end{tabular}

Note: ${ }^{\star \star \star}$ denotes $\mathrm{p}<0.01 ;{ }^{\star \star}$ denotes $\mathrm{p}<0.05 ;{ }^{\star}$ denotes $\mathrm{p}<0.1$.

In order to reach a more comprehensive analyzed outcome, we measure multiple DEA specifications (i.e., two input variables and three output variables can generate 21 dissimilar combinations) (see Table 2) together with financial indicators (i.e., sales growth rate: SGR; earnings per share: EPS; earnings before interest and tax: EBIT; inventory turnover rate: ITR). We perform a visualization algorithm - namely, multidimensional scaling (MDS), which highlights the essential characteristics of the information hidden in the data - to make the results much more accessible to non-specialists. The basic concept of this method is to measure the proximity between pairs of samples. The samples are located close to each other implies that their proximity is high (Sagarra et al., 2017). By doing so, we can divide the objects into two groups: superior and inferior group (see Figure 1). 
Table 2. Multiple DEA specifications

\begin{tabular}{|c|c|c|}
\hline DEA Specification & Input (IP): TL (IP1), TE (IP2) & Output (OP): PR(OP1), ROA(OP2), ROE(OP3) \\
\hline DEA-S1 & IP1 & OP1 \\
\hline DEA-S2 & IP1 & OP2 \\
\hline DEA-S3 & IP1 3 \\
\hline DEA-S4 & IP1 & OP1, OP2 \\
\hline DEA-S5 & IP1 & OP1, OP3 \\
\hline DEA-S6 & IP1 & OP2, OP3 \\
\hline DEA-S7 & IP1 & OP1, OP2, OP3 \\
\hline DEA-S8 & IP2 & OP1 \\
\hline DEA-S9 & IP2 2 \\
\hline DEA-S10 & IP2 & OP3 \\
\hline DEA-S11 & IP2 OP2 & OP1, OP3 \\
\hline DEA-S12 & IP2 & OP2, OP3 \\
\hline DEA-S13 & IP2 & OP1, OP2, OP3 \\
\hline DEA-S14 & IP2 & OP1 \\
\hline DEA-S15 & IP1, IP2 & OP2 \\
\hline DEA-S16 & IP1, IP2 & OP3 \\
\hline DEA-S17 & IP1, IP2 & OP1, OP2 \\
\hline DEA-S18 & IP1, IP2 & OP1, OP3 \\
\hline DEA-S19 & IP1, IP2 & OP1, OP2, OP3 \\
\hline DEA-S20 & IP1, IP2 & \\
\hline DEA-S21 & IP1, IP2 & OP2 \\
\hline
\end{tabular}

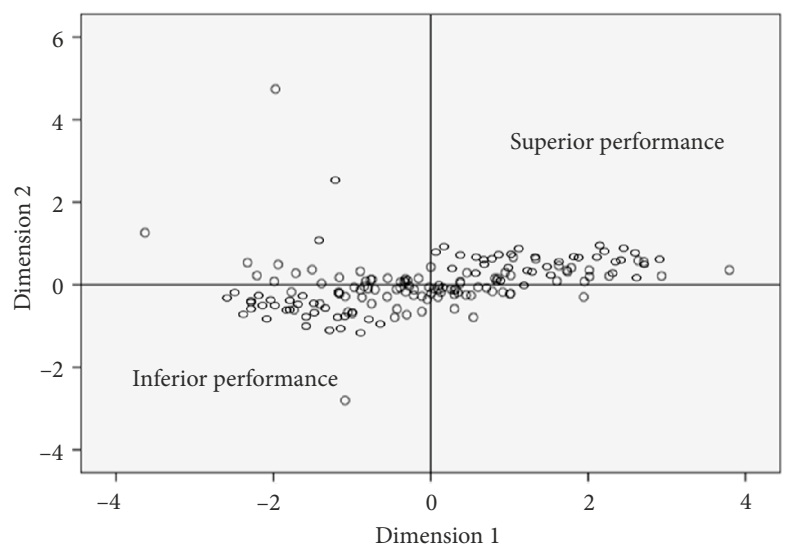

Figure 1. The discriminant result 


\subsection{The independent variable}

Almost 99\% of financial distress cases have resulted from bad operating performance (Kamei, 1997). In other words, bad operating performance not only can be viewed as the preceding stage before financial distress bursts out, but also can be deemed as the main trigger for financial distress (Chang, Hsu, \& Lin, 2018). Thus, the selected variables used in financial distress can be designated as predictors in this study. Table 3 lists the selected variables.

Table 3. The independent variables

\begin{tabular}{|c|l|}
\hline Symbol & \multicolumn{1}{|c|}{ Illustration } \\
\hline S1:S/TA & Sales to total assets \\
\hline S2: TD/TA & Total liability to total assets \\
\hline S3: AR/S & Account receivable to sales \\
\hline S4: I/TA & Inventory to total assets \\
\hline S5: WC/TA & Working capital to total assets \\
\hline S6: NP/TA & Net profit to total assets \\
\hline S7: GP/TA & Gross profit to total assets \\
\hline S8: AR/TA & Account receivable to total assets \\
\hline S9: RE/TA & Retained earnings to total assets \\
\hline S10: EBIT/TA & Earnings before interest and tax to total assets \\
\hline
\end{tabular}

The resource based view (RBV) theory supports the assumption that a corporate acquiring a competitive edge relies heavily on the application of its bundle of physical productive resources (Wernerfelt, 1984; Barney, 2001). Grounded on this theory, corporate resources (i.e., capital, land, and human labor) are valuable, rare, distinctive, and inimitable and can be recognized as important sources of competitive edge and superior operating performance (Peteraf, 1993). However, with the development of information technology, the element of any value-creating process has shifted from tangible assets to intangible assets. Utilizing cyberspace and web-technology turns out to be a common practice for all businesses in today's modern economy (Zhang, Shi, Wang, \& Fang, 2018). Corporates are empowered to contact their SC partners, customers, and clients anytime from anywhere by the Internet (Chen \& Chiang, 2011; Liu \& Cruz, 2012; Huang, Ho, \& Chiu, 2014). Walter, Auer, and Ritter (2006) stated that operating performance outcome can be improved by developing strong relationships with market participants, thus facilitating knowledge sharing and enhancing customers' purchasing intention. Gensler, Volckner, Liu-Thompkins, and Wiertz (2013) also indicated that corporates are highly embedded in their SC collaboration networks, which contribute greatly to their operating performance. Unfortunately, due to the opaque nature of a corporate's business relationships and difficult at gathering such data, there are few research works in the literature depicting real-life SC collaboration networks (Kim et al., 2011).

To fill this vacancy left in the literature, this work is grounded on prior research work done by Bao et al. (2008), who noted that corporates showing in the same piece of news imply that there may possibly have some relationship among them. To make our SC network much 
more concrete, we conduct a domain-specific word list (i.e., cooperate, collaborate, team, supply, transport, partner, ally, procure, purchase, joint, and coordinate). Furthermore, by making use of Yahoo!Kimo's specific organizing style, we extract a firm's stock ticker information by TM and then utilize it to construct the SC collaboration networks (see Figure 2). We totally gathered around 10,000 news article from social media (i.e., Yahoo!Kimo) during the period from 2015 to 2017 . We take the degree of centrality that counts how many neighbors a node has to construct the forecasting model.

The financial ratios calculated from financial statements could hide some details about financial troubles by means of selective accounting principles and different estimation methods. Generally speaking, the changing signal of a corporate operating performance is more likely to appear in a textual format (i.e., accounting narrative or news article) before any subtle modification shows up in financial ratios. Disclosure in the Management's Discussion and Analysis (MD\&A) section has been widely considered as a vital conduit of narrative information to market participants. We describe three principle objectives for MD\&A as

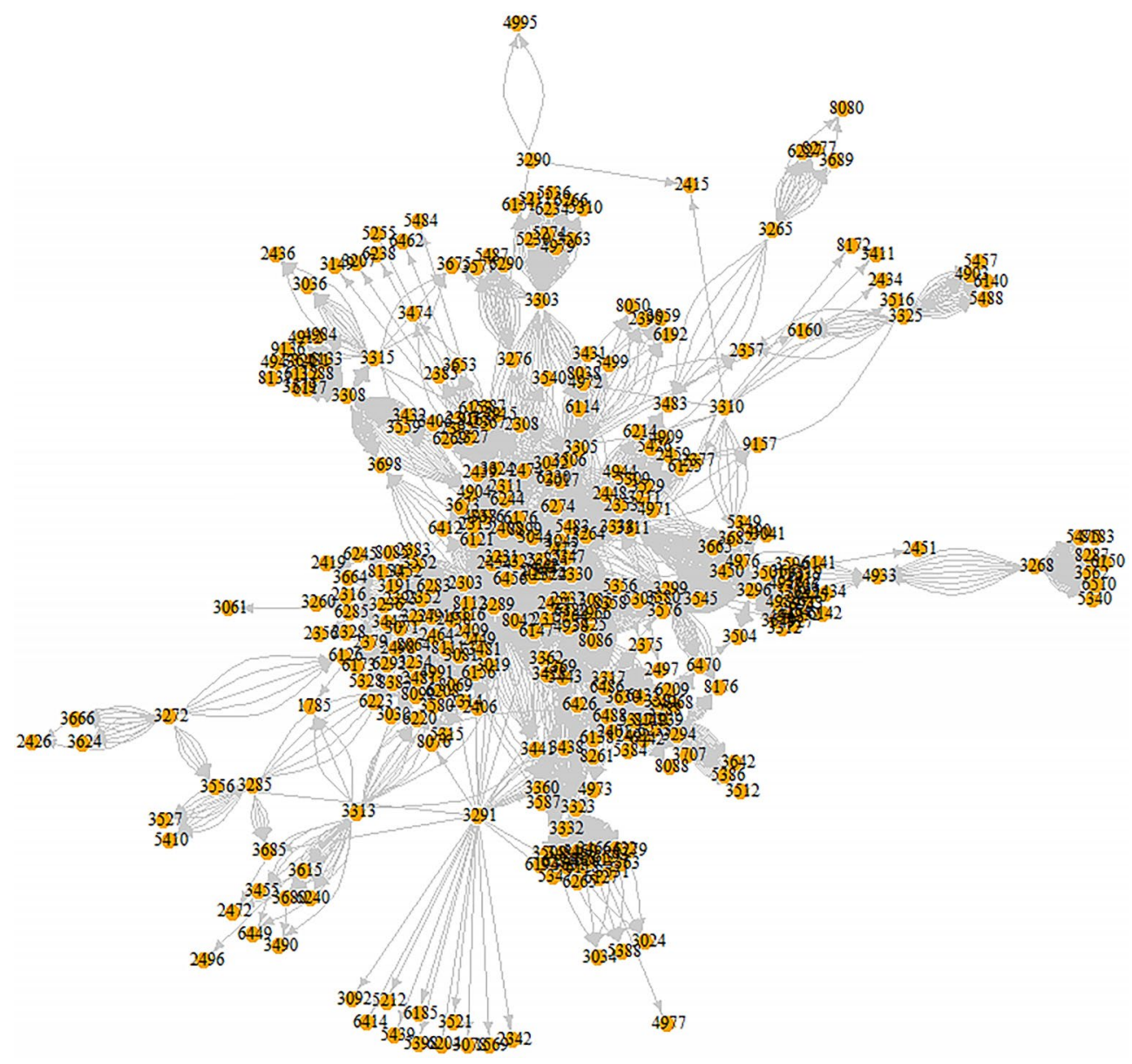

Figure 2. The SC collaboration networks 
follows (Li, 2010; Loughran \& McDonald, 2011): (1) To solidify financial transparency and yield the context under which financial information should be evaluated; (2) To provide a narrative explanation of a corporate's operating status that enables market participants to realize much more the real status of its operations; and (3) To yield useful message about the quality and variability of future cash flow or earnings. Epstein and Palepu (1999) stated that investors should rely more heavily on MD\&A than audited financial statements. Based on this concept, we believe that the sentiment in the MD\&A section should contain some essential information. Lougharn and McDonald (2011) proposed a specific dictionary for the financial domain that consists of six sentiment categories. By matching the content of MD\&A with this sentiment dictionary, we can obtain the sentiment indicator and use it to construct the forecasting model.

\subsection{The measurement criteria}

There are many measurement criteria introduced for the forecasting task, with the most widely utilized criteria being overall accuracy. However, only utilizing one measurement criterion to judge the model's performance and reach a final conclusion is not a reliable and trustful way (Hsu, Yeh, \& Lin, 2018). Thus, two other measurement criteria, "type I error: it means that a corporate with superior operating performance has been misclassified as an inferior one" and type II error: it denotes that a corporate with inferior operating performance has been misclassified as a superior one", are executed. The former may result in additional investigation, and the latter may result in ruining a corporate's value as well as lead to fatal economic losses. Table 4 shows the confusion matrix.

Table 4. Confusion matrix

\begin{tabular}{|l|c|c|}
\hline Actual Forecasted & Superior efficiency & Inferior efficiency \\
\hline Superior efficiency & I & II \\
\hline Inferior efficiency & III & IV \\
\hline
\end{tabular}

Overall accuracy $(\mathrm{OA})=(\mathrm{I}+\mathrm{II}) /(\mathrm{I}+\mathrm{II}+\mathrm{III}+\mathrm{IV})$;

Type I error = II /(I + II);

Type II error = III /(III + IV).

\subsection{The forecasting results}

Most financial variables derived from financial statements contain some degree of errors. Thus, feature selection (FS) is a necessary and inevitable pre-process (Chang \& Hsu, 2018). The purpose of FS is to find a core subset from a problem domain without deteriorating the model's classification accuracy and appropriately representing the structure of the original features. Pawlak (1982) introduced a rough set theory (RST) that not only can deal with data containing impreciseness, uncertainty, and vagueness, but also can identify the dependency of the data and eliminate the number of used features without requiring extra information 
(Bai \& Sarkis, 2018; Chang \& Hsu, 2018; Hsu, 2018). How to generate the minimal reduct (i.e., the best feature subset) for RST has thus been proven to be a NP-hard problem (Chen, $\mathrm{Zhu}, \& \mathrm{Xu}, 2015)$.

This study employs a new swarm intelligence approach, fish swarm algorithm (FSA) (Li, Shao, \& Qian, 2002), which has the merits of a strong capability to escape from local minimums, a faster convergence rate, and intuitive mathematical formulation, in order to determine the best feature subset for RST (see Figure 3). To examine the effectiveness of FS, we consider two scenarios: (1) with FS and (2) without FS. To access a more robust outcome, we take the introduced model as a benchmark and compare it with four other models for predicting financial troubles, such as Bayesian belief network (BBN) (Kirkos, Spathis, \& Manolopoulos, 2007), Adaptive neuro fuzzy inference system (ANFIS) (Pan, 2009), Support vector machine (SVM) (Shie, Chen, \& Liu, 2012), and extreme learning machine (ELM) (Lin, 2017). To avoid the result just happening by chance, we perform a statistical examination. The results appear in Table 5. We can see that the model with FS can increase forecasting quality as well as lower the number of misclassification errors. The outcome is in accordance with the work done by Uysal and Gunal (2012) who indicated that FS can boost the performance of the classification model as well as eliminate the impact of dimensionality.

One of the interesting finding is that a corporate's SC influential indicator (SCI) (i.e., it represents the level of a corporate's involvement in a SC collaboration relationship network) and sentimental indicator (STI) are included in the minimal reduct determined by RST. It implies that both indicators are essential and have a considerable influence on the model's classification accuracy. To test the influence of each indicator, we set up four scenarios: (1) without SCI and STI, (2) with SCI, (3) with STI, and (4) with SCI and STI. One of the nonparametric statistics, called the Friedman test, poses the advantage of easy-to-use, depicts the synthesized outcome of models in the ranking format instead of dubious averages, and is taken as a measurement criterion under several of our comparisons (Demsar, 2006). Figures 4-6 present the results. We can see that the model with SCI outperforms the model without SCI.

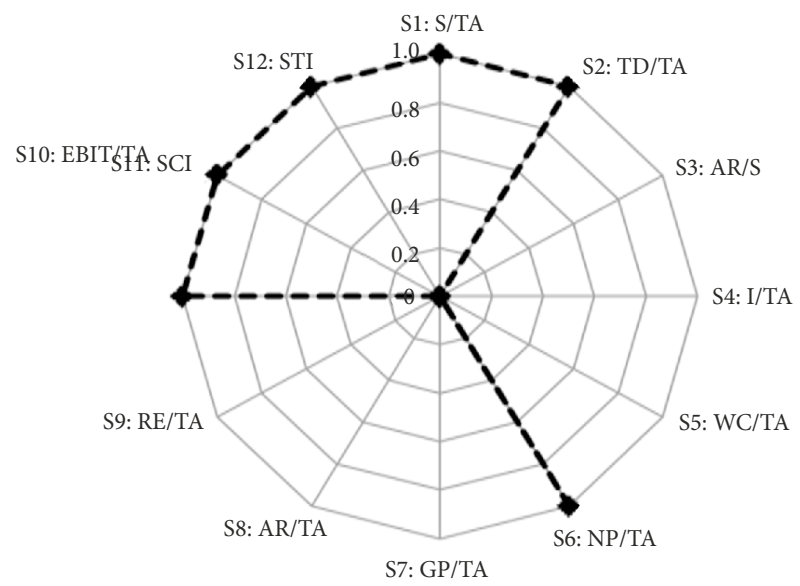

Figure 3. The selected features by RST 
Table 5. The results

\begin{tabular}{|c|c|c|c|}
\hline \multirow{3}{*}{ Model } & \multicolumn{2}{|c|}{ Scenario } & \multirow{3}{*}{$\begin{array}{l}\text { Statistical result } \\
\qquad(\mathrm{p}=\text { value })\end{array}$} \\
\hline & With FS & Without FS & \\
\hline & \multicolumn{2}{|c|}{ Measurement criteria: ACC } & \\
\hline Proposed model & 87.45 & 79.45 & $\mathrm{P}=0.006^{\star * *}$ \\
\hline ANFIS & 77.05 & 69.45 & $\mathrm{P}=0.000^{\star * \star}$ \\
\hline BBN & 69.65 & 61.60 & $\mathrm{P}=0.000^{\star * \star}$ \\
\hline ELM & 82.30 & 75.70 & $\mathrm{P}=0.000^{\star * *}$ \\
\hline SVM & 83.90 & 76.00 & $\mathrm{P}=0.031^{\star \star}$ \\
\hline \multicolumn{4}{|c|}{ Measurement criteria: (100-Type I error) } \\
\hline Proposed model & 88.60 & 80.10 & $\mathrm{P}=0.003^{\star * *}$ \\
\hline ANFIS & 75.40 & 67.60 & $\mathrm{P}=0.000^{\star * *}$ \\
\hline BBN & 70.00 & 62.20 & $\mathrm{P}=0.002^{\star \star *}$ \\
\hline ELM & 84.30 & 77.70 & $\mathrm{P}=0.007^{\star * *}$ \\
\hline SVM & 83.90 & 75.30 & $\mathrm{P}=0.014^{\star \star}$ \\
\hline \multicolumn{4}{|c|}{ Measurement criteria: (100-Type II error) } \\
\hline Proposed model & 86.30 & 78.80 & $\mathrm{P}=0.015^{\star *}$ \\
\hline ANFIS & 78.70 & 71.10 & $\mathrm{P}=0.000^{\star *}$ \\
\hline BBN & 69.03 & 61.00 & $\mathrm{P}=0.002^{\star \star}$ \\
\hline ELM & 80.30 & 73.70 & $\mathrm{P}=0.000^{* * *}$ \\
\hline SVM & 83.90 & 76.70 & $\mathrm{P}=0.041^{\star *}$ \\
\hline
\end{tabular}

Note: ${ }^{*}$ denotes $\mathrm{p}<0.1 ;{ }^{* *}$ denotes $\mathrm{p}<0.05 ;{ }^{* *}$ denotes $\mathrm{p}<0.01$.

This outcome is in line with Dyer and Nobeoka (2000), who empirically proved that a higher degree of interconnection in a SC network lowers the cost of transaction (such as monitoring, and negotiating) considerably. Gnyawali and Madhaven (2001) further indicated that a corporate's position located on SC network can be viewed as its competitive advantage and bring informational and reputational priorities.

The forecasting model with STI still outperforms the model without STI. This outcome is the same with Magnusson et al. (2005), who indicated that when a corporate is expected to perform well, the sentiment of the accounting narrative document (i.e., MD\&A) tends to be positive. To our knowledge, none of the current research studies utilize SCI together with STI to construct the performance forecasting model. To fill this gap, two different kinds of soft information are taken. The result shows that this model with two different kinds of soft information performs better than the model without two different kinds of soft information. West et al. (2005) also indicated that even a little improvement in preciseness can bring huge amount of future profits to market participants. Thus, the two different kinds of soft information should be taken simultaneously by decision makers to form a final judgment. 


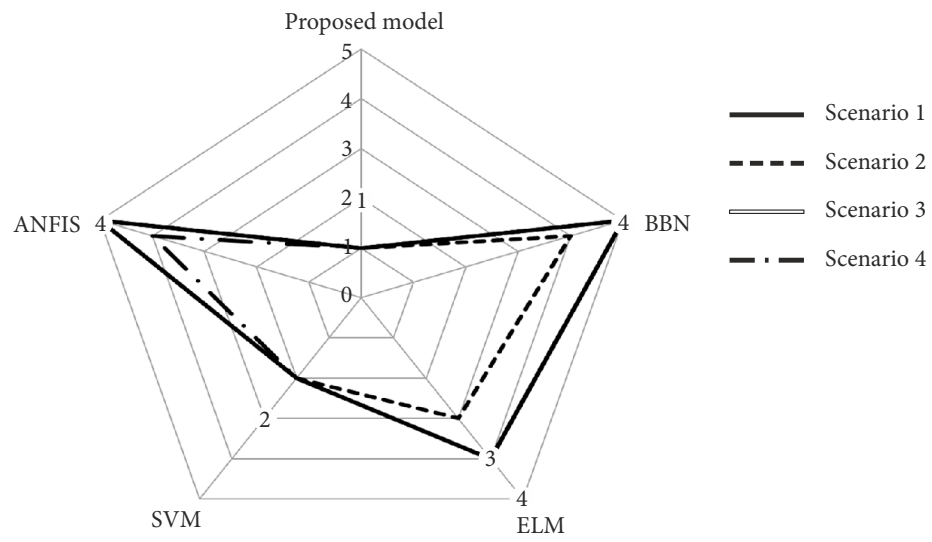

Figure 4. The results (ACC)

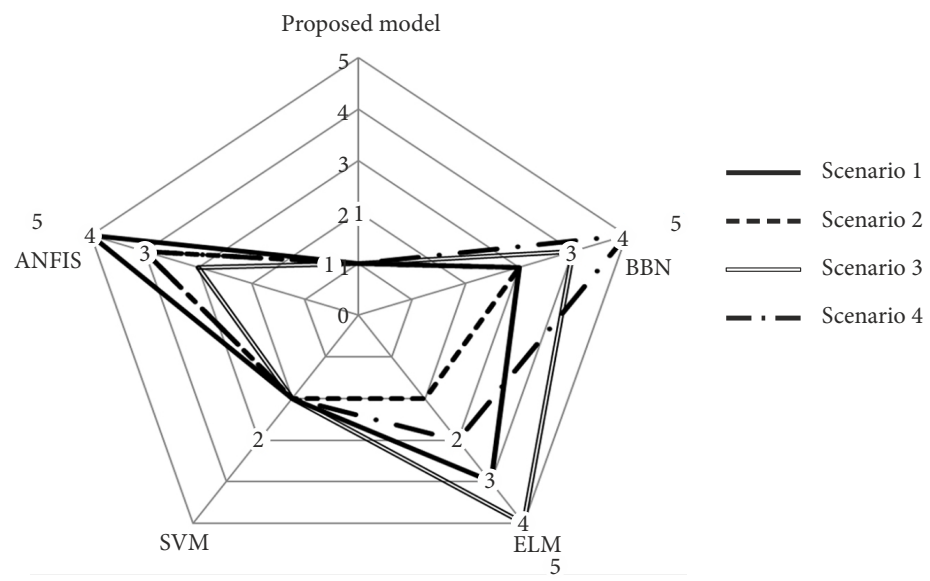

Figure 5. The result (100-Type I error)

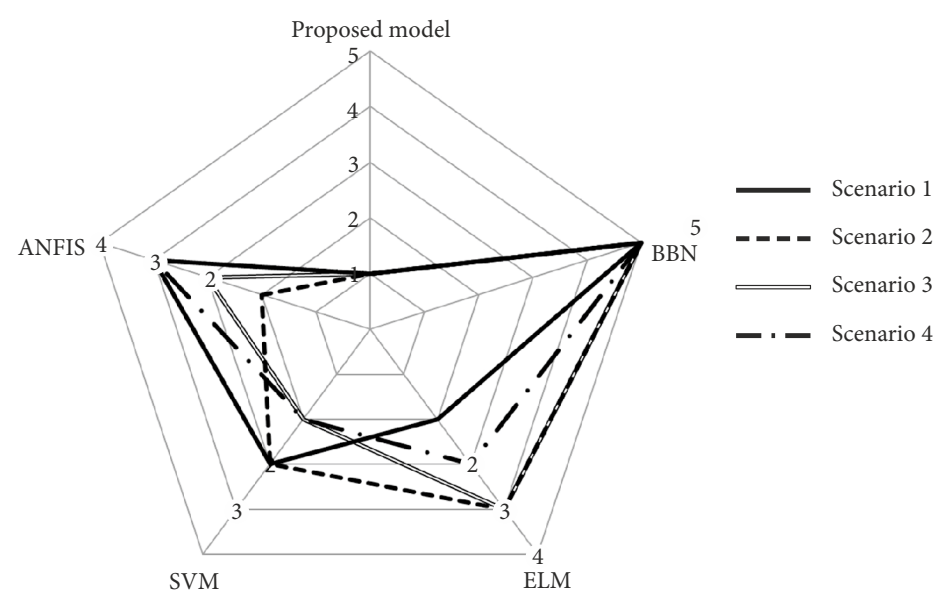

Figure 6. The result (100-Type II error) 


\subsection{Robustness test}

Reaching an ultimate conclusion only by relying on one pre-decided dataset is not appropriate and reliable in today's highly volatile environment. To robust our research findings, we consider another two different datasets: (1) performance rank determined by the original DEA, and (2) performance rank determined by ROA. Table 6 depicts the difference between the original DEA and multiple DEA specifications in discriminant capability. We can see that multiple DEA specifications perform better than the original DEA in discriminant capability. In other words, the performance scores determined by multiple DEA specifications have lower mean and higher variance values. This outcome is in response to Sagarra et al. (2017) who indicated that the utilization of a different set of efficiency scores (i.e., multiple DEA specifications) provides a broader set of information for discriminating and grouping the observed units as well as reaches a more robust result. Moreover, to ensure the selected performance measures are fairly representative, we take each corporate's credit rating status into consideration. A corporate's credit rating status is assessed by professional and independent agencies that aim to find out how it might be unable to meet its financial obligation and specifically rests on a complete and overarching analysis of all the risk elements of the measured objects. The utilization of credit status is widely being taken as an assessment of corporate's risk and creditworthiness. The rating status can be divided into 10 ranks, ranging from best to worst (ranks 1 to 4 express low risk; 5-6 express middle risk; 7 to 10 express high risk). Figure 7 expresses the results under two different performance measures (original DEA vs. multiple DEA specifications). We can see that a corporate with superior performance determined by multiple DEA specifications usually has a better credit rating status. In contrast, most corporates with better performance derived from original DEA still have a bad credit rating status - that is, multiple DEA specifications' discriminant ability is better than the original DEA. Tables $7-8$ show the forecasting performance under two different datasets. We can see that the introduced model still reaches optimal performance under the whole assessment criteria for the two dissimilar datasets.

Table 6. The compared results

\begin{tabular}{|l|c|c|}
\hline \multicolumn{1}{|c|}{ Condition } & Mean & Variance \\
\hline Original DEA & 0.872 & 0.06 \\
\hline Multiple DEA specifications & 0.723 & 0.13 \\
\hline
\end{tabular}

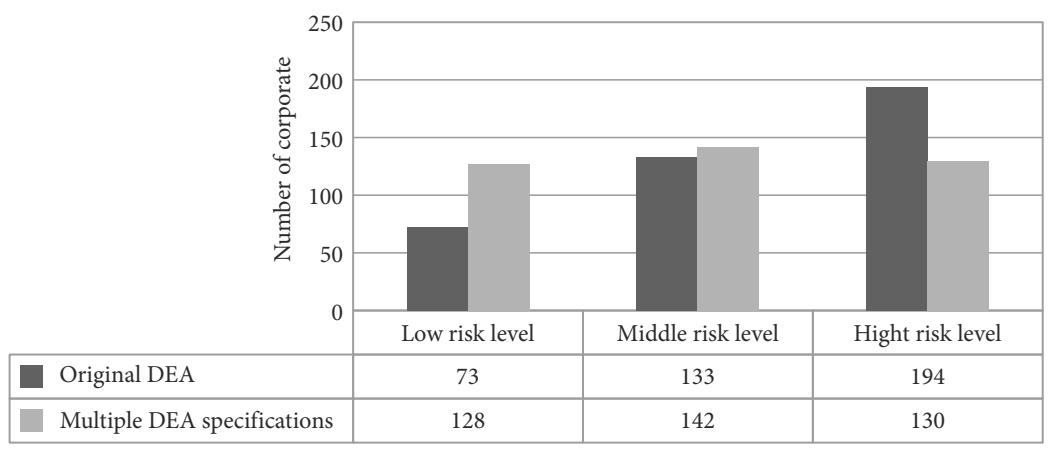

Figure 7. The discriminant ability of two assessment measures 
Table 7. The Friedman test results (performance rank determined by original DEA)

\begin{tabular}{|l|c|c|c|}
\hline \multirow{2}{*}{ Model } & \multicolumn{3}{|c|}{ Mean value of criterion (ranks) (\%) } \\
\cline { 2 - 4 } & ACC & 100 -Type I error & 100 -Type II error \\
\hline Proposed model & $86.75(1)$ & $87.50(1)$ & $86.00(1)$ \\
\hline BPNN & $71.75(5)$ & $70.50(5)$ & $73.00(5)$ \\
\hline ELM & $79.75(4)$ & $82.00(4)$ & $77.50(4)$ \\
\hline SVM & $84.25(2)$ & $85.00(2)$ & $83.50(2)$ \\
\hline RVM & $82.50(3)$ & $82.00(3)$ & $83.00(3)$ \\
\hline p-value & $\mathrm{P}=0.000^{* * *}$ & $\mathrm{P}=0.000^{* * *}$ & $\mathrm{P}=0.000^{* * *}$ \\
\hline
\end{tabular}

Note: ${ }^{\star}$ denotes $\mathrm{p}<0.1 ;{ }^{\star \star}$ denotes $\mathrm{p}<0.05 ;{ }^{\star * \star}$ denotes $\mathrm{p}<0.01$.

Table 8. The Friedman test results (performance rank determined by ROA)

\begin{tabular}{|l|c|c|c|}
\hline \multirow{2}{*}{ Model } & \multicolumn{3}{|c|}{ Mean value of criterion (ranks) (\%) } \\
\cline { 2 - 4 } & ACC & 100 -Type I error & 100 -Type II error \\
\hline Proposed model & $81.75(1)$ & $82.00(1)$ & $81.50(1)$ \\
\hline BPNN & $69.00(5)$ & $67.00(5)$ & $71.00(5)$ \\
\hline ELM & $73.75(4)$ & $76.50(2)$ & $71.00(4)$ \\
\hline SVM & $75.50(2)$ & $74.50(3)$ & $76.50(3)$ \\
\hline RVM & $74.00(3)$ & $70.50(4)$ & $77.50(2)$ \\
\hline p-value & $\mathrm{P}=0.000^{* * *}$ & $\mathrm{P}=0.000^{* *}$ & $\mathrm{P}=0.032^{* *}$ \\
\hline
\end{tabular}

Note: ${ }^{\star}$ denotes $\mathrm{p}<0.1 ;{ }^{* *}$ denotes $\mathrm{p}<0.05 ;{ }^{* *}$ denotes $\mathrm{p}<0.01$.

\subsection{Description of decision logics}

The NN-based mechanism poses outstanding generalization capability, but it encounters a severe weakness from its lack of understandability - that is, the inherent decision-making concept embedded in the NN-based mechanism are implicit and opaque. If the model's forecasted outcome cannot be realized and re-checked by users, then they would have a higher intention to not use the model as well as impede its practical applications. How to extract the inherent decision-making concepts from the NN-based mechanism and represent the concepts in an intuitive and human readable format turns out to be a crucial requirement for the acceptance of black-box models. This study treats RVFL, one type of a NN-based mechanism, as a black-box and extracts the decision rules that depict the relationship between the model's inputs and outputs. The fundamental idea is to construct an artificially labelled case where the target class label of the training dataset is substituted by RVFL's forecasted outcome. Sequentially, we feed the artificial dataset into another model with explanation capability that can learn what RVFL has learned. Decision tree (DT) has superior forecasting quality with a relatively small computational burden and can discover useful patterns as well as yield intuitive decision rules for decision makers. Thus, we utilize DT to handle the task of knowledge extraction. 


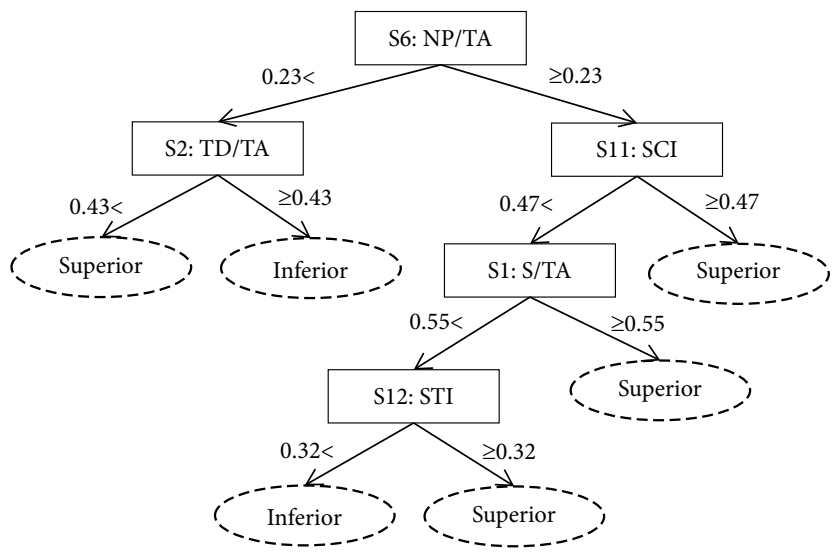

Figure 8. The decision rules

Figure 8 depicts the decision rules. We can realize that a corporate with superior performance normally presents a higher profit margin, suitable capital structure, efficient asset utilization, and greater involvement in the SC collaboration relationship network (Ramanathan, Ramanathan, \& Bentley, 2018). From the results, the government can consider potential implications to announce future beneficial policies. For example, if the government wants to upgrade the nation's industrial level, then it can allocate much more resources on some specific corporates that are highly involved in their SC collaboration relationship network. The reason is that such high involvement in a SC network can facilitate better resource and knowledge sharing, decrease risk exposure and uncertainty, increase profit margin, and strengthen the firms' competitive edge. Top-level managers can take the proposed model as a roadmap to allocate valuable resources to more suitable places, modify their firm's financial leverage to minimize the cost of the capital, and react quicker to customers' requirements. Market participants also can view the extracted knowledge (i.e., decision rules) as a navigating principle to adjust their investment portfolio and financing strategies in order to fulfill the goal of profit maximization under an endurable risk level.

\section{Conclusions and future works}

Bad corporate operating performance is responsible for $99 \%$ of financial distressed cases, and therefore it can be viewed as the primary trigger for financial troubles. However, works on performance prediction are quite scarce compared to the well-established literature on financial distress prediction and credit risk prediction. To fill this vacancy, the study introduces a sophisticated framework that integrates multiple DEA specifications, MDS, TM, SNA, sentimental analysis, and AI technique for operating performance evaluation and forecasting. Through joint utilization of multiple DEA specifications and financial indicators, we are able to obtain a more overarching description on a corporate's operations. To make the analyzed outcome more accessible to non-specialists, we employ MDS to visualize the main characteristics of the data. By doing so, users can appropriately see which corporates belong to the superior group and which ones belong to the inferior group. 
Compared to multinationals and global enterprises, domestic corporates usually have limited human capital and scarce financial resources and are unlikely to exist for a long term. Greater involvement in a corporate's SC collaboration relationship network has been widely deemed as an effective manner to response to the shocks of globalization, but it is very complicated to determine a corporate's SC relationships due to their implicit and opaque nature. Through a mixture of TM and SNA, we can realize a corporate's involvement in its SC network and further examine the network's influence on its operating performance.

Most previous works on financial forecasting model construction have relied heavily on hard information (i.e., financial ratios) that is collected from financial statements. However, these ratios may be contaminated to some degree by errors due to manager's discretion ability, such as dissimilar estimation approaches, and selective accounting principles. Broadly speaking, the changing signal of a corporate's financial status is more likely to appear in soft information (i.e., sentiment, opinion, news, and accounting narratives) before any subtle modifications show up in hard information. Thus, we believe that soft information (which denotes sentiment in this study) usually holds some message about future corporate operating performance, and thus we conduct sentimental analysis.

We sequentially feed the analyzed result into RVFL to construct the forecasting model. To our knowledge, no current research has taken both SCI and STI into consideration, and hence even a fraction of improvement in the model's forecasting accuracy can transmit considerable future savings to market participants and corporates. To reach a more robust outcome, we therefore simultaneously take two indicators (i.e., SCI and STI) to establish the model for performance forecasting. The result indicates that the model with two indicators reaches optimal forecasting quality, which is in accordance with Kim (2014) and Bhattacharjee and Cruz (2015), who indicated that a corporate with a higher involvement in its SC network can assist other corporates in reacting to changes in the market, shorten product lead times, increase customer loyalty and values, and enlarge profit margins by means of utilizing the network for transmitting essential knowledge, information, opportunities, and resources. Furthermore, the result also corresponds to Loughran and McDonald (2011), who stated that the context-sensitive knowledge (i.e., sentiment/tone/opinion) provided in annual reports significantly correlates with profitability, trading volume, and performance.

A lack of comprehensibility is one of the severe obstacles of a NN-based mechanism (i.e., RVFL). To overcome this obstacle, we employ DT grounded on a pedagogical structure to extract the inherent judgments from RVFL and represent them in an easy-to-use and intuitive manner in order to enhance its real-life utilization. The introduced framework, tested by real cases, is a promising alternative for performance forecasting task.

Future works can consider two potential research directions. First, because RVFL is an efficient and effective learning algorithm with the property of fast learning, it has attracted considerable attentions in many research fields. In reality, the selection of network parameters for RVFL significantly influences forecasting quality. To cope with the aforementioned task, parameter selection can be converted into an optimization task and one can use a metaheuristic algorithm to solve it. In addition, the introduced model herein belongs to the class of singular models that contain only one classifier. However, no specific model can achieve the optimal forecasting outcome under all scenarios. Inspired by the idea of classifier 
ensemble, which aims to complement the error made by a single mechanism, the proposed model can be extended to an ensemble structure so as to increase forecasting performance. Second, feature research can use more advanced feature selection techniques to determine the essential feature subset. This is because the original RST only accepts discrete data. Data going through a discretization procedure will incur the problem of information loss. To overcome this task, fuzzy RST can be used in the future.

\section{Acknowledgements}

The authors would like to thank the Ministry of Science and Technology, Taiwan, R.O.C. for financially supporting this work under contracts No.106-2410-H-034 -046 -MY2, No. 1062410-H-034 -011 -MY3, No. 107-2410-H-110 -025 -MY2, and 108-2410-H-034 -056 -MY2

\section{Author contributions}

Dr. Hsu and Dr. Chang are conceived the study and were responsible for the design and development of the data analysis. I was responsible for data collection and analysis as well as data interpretation.

\section{Disclosure statement}

No conflict of interest exists in the submission of this manuscript.

\section{References}

Bao, S., Li, R., Yu, Y., \& Cao, Y. (2008). Competitor mining with the Web. IEEE Transactions on Knowledge and Data Engineering, 20, 1297-1310. https://doi.org/10.1109/TKDE.2008.98

Beamon, B. M. (1999). Designing the green supply chain. Logistics Information Management, 12(4), 332-342. https://doi.org/10.1108/09576059910284159

Barney, J. B. (2001). Resource-based theories of competitive advantage: A ten-year retrospective on the resource-based view. Journal of Management, 27(6), 643-650. https://doi.org/10.1177/014920630102700602

Bai, C., \& Sarkis, J. (2018). Evaluating complex decision and predictive environments: the case of green supply chain flexibility. Technological and Economic Development of Economy, 24(4), 1630-1658. https://doi.org/10.3846/20294913.2018.1483977

Beattie, V., Mcinnes, B., \& Fearnley, S. (2004). A methodology for analysing and evaluating narratives in annual reports: a comprehensive descriptive profile and metrics for disclosure quality attributes. Accounting Forum, 28(3), 205-236. https://doi.org/10.1016/j.accfor.2004.07.001

Bhattacharjee, S., \& Cruz, J. (2015). Economic sustainability of closed loop supply chains: A holistic model for decision and policy analysis. Decision Support Systems, 77, 67-86. https://doi.org/10.1016/j.dss.2015.05.011

Çalik, A., Yapici Pehlivan, N., \& Kahraman, C. (2018). An integrated fuzzy AHP/DEA approach for performance evaluation of territorial units in Turkey. Technological and Economic Development of Economy, 24(4), 1280-1302. https://doi.org/10.3846/20294913.2016.1230563 
Cinca, C. S., \& Molinero, C. M. (2004). Selecting DEA specifications and ranking units via PCA. Journal of the Operational Research Society, 55(5), 521-528. https://doi.org/10.1057/palgrave.jors.2601705

Charnes, A., Cooper, W. W., \& Rhodes, E. (1978). Measuring the efficiency of decision making units. European Journal of Operational Research, 2(6), 429-444. https://doi.org/10.1016/0377-2217(78)90138-8

Charnes, A., \& Cooper, W. W. (1962). Programming with linear fractional functions. Naval Research Logistics Quarterly, 9, 181-186. https://doi.org/10.1002/nav.3800090303

Chang, T. M., Hsu, M. F., \& Lin, S. J. (2018). Integrated news mining technique and AI-based mechanism for corporate performance forecasting. Information Sciences, 424, 273-286. https://doi.org/10.1016/j.ins.2017.10.004

Chang, T. M., \& Hsu, M. F. (2018). Integration of incremental filter-wrapper selection strategy with artificial intelligence for enterprise risk management. International Journal of Machine Learning and Cybernetics, 9, 477-489. https://doi.org/10.1007/s13042-016-0545-8

Chen, C. M., \& Zhu, J. (2011). Efficient resource allocation via efficiency bootstraps: An application to R\&D project budgeting. Operations Research, 59, 729-741. https://doi.org/10.1287/opre.1110.0920

Chen, W. H., \& Chiang, A. H. (2011). Network agility as a trigger for enhancing firm performance: A case study of a high-tech firm implementing the mixed channel strategy. Industrial Marketing Management, 40(4), 643-651. https://doi.org/10.1016/j.indmarman.2011.01.001

Chen, Y., Zhu, Q., \& Xu, H. (2015). Finding rough set reducts with fish swarm algorithm. KnowledgeBased Systems, 81, 22-29. https://doi.org/10.1016/j.knosys.2015.02.002

Demsar, J. (2006). Statistical comparisons of classifiers over multiple data sets. Journal of Machine Learning Research, 7, 1-30.

Dyer, J., \& Nobeoka, K. (2000) Creating and managing a high-performance knowledge-sharing network: The Toyota case. Strategic Management Journal, 21, 345-367. https://doi.org/10.1002/(SICI)1097-0266(200003)21:3<345::AID-SMJ96>3.0.CO;2-N

Epstein, M. J., \& Palepu, K. G. (1999). What financial analysts want. Strategic Finance, 80(10), 48-52.

Eskandarpour, M., Dejax, P., Miemczyk, J., \& Péton, O. (2015). Sustainable supply chain network design: An optimization-oriented review. Omega, 54, 11-32. https://doi.org/10.1016/j.omega.2015.01.006

Friedman, J., Hastie, T., \& Tibshirani, R. (2009). The elements of statistical learning (2nd ed.). New York: Springer. https://doi.org/10.1007/978-0-387-84858-7

Forero, P. A., Cano, A., \& Giannakis, G. B. (2010). Consensus-based distributed support vector machines. Journal of Machine Learning Research, 11, 1663-1707. https://doi.org/10.1145/1791212.1791218

Gajzler, M. (2010). Text and data mining techniques in aspect of knowledge acquisition for decision support system in construction industry. Technological and Economic Development of Economy, 16(2), 219-232. https://doi.org/10.3846/tede.2010.14

Gensler, S., Volckner, F., Liu-Thompkins, Y., \& Wiertz, C. (2013). Managing brands in the social media environment. Journal of Interactive Marketing, 27(4), 242-256.

https://doi.org/10.1016/j.intmar.2013.09.004

Georgopoulos, L., \& Hasler, M. (2014). Distributed machine learning in networks by consensus. Neurocomputing, 124, 2-12. https://doi.org/10.1016/j.neucom.2012.12.055

Gnyawali, D., \& Madhaven, R. (2001). Cooperative networks and competitive dynamics: A structural embeddedness perspective. Academy of Management Review, 26(3), 431-445. https://doi.org/10.5465/amr.2001.4845820

Hajek, P., Olej, V., \& Myskova, R. (2014). Forecasting corporate financial performance using sentiment in annual reports for stakeholders' decision-making. Technological and Economic Development of Economy, 20(4), 721-738. https://doi.org/10.3846/20294913.2014.979456

Huang, C., Ho, F. N., \& Chiu, Y. (2014). Measurement of tourist hotels' productive efficiency, occupancy, and catering service effectiveness using a modified two-stage DEA model in Taiwan. Omega, 48, 49-59. https://doi.org/10.1016/j.omega.2014.02.005 
Huang, A., Zang, A., \& Zheng, R. (2014). Evidence on the information content of text in analyst reports. Accounting Review, 89, 2151-2180. https://doi.org/10.2308/accr-50833

Hu, K. H., Jianguo, W., \& Tzeng, G. H. (2018). Improving China’s regional financial center modernization development using a new hybrid MADM model. Technological and Economic Development of Economy, 24(2), 429-466. https://doi.org/10.3846/20294913.2016.1213195

Hsu, M. F., Yeh, C. C., \& Lin, S. J. (2018). Integrating dynamic Malmquist DEA and social network computing for advanced management decisions. Journal of Intelligent \& Fuzzy Systems, 35(1), 231241. https://doi.org/10.3233/JIFS-169583

Hsu, M. F. (2019a). Integrated multiple-attribute decision making and kernel-based mechanism for risk analysis and evaluation. Journal of Intelligent \& Fuzzy Systems, 36(3), 2895-2905. https://doi.org/10.3233/JIFS-171366

Hsu, M. F. (2019b). A fusion mechanism for management decision and risk analysis. Cybernetics and Systems, 50(6), 497-515. https://doi.org/10.1080/01969722.2018.1541596

Igelnik, B., \& Pao, Y. H. (1995). Stochastic choice of basis functions in adaptive function approximation and the functional-link net. IEEE Transactions on Neural Networks, 6(6), 1320-1329. https://doi.org/10.1109/72.471375

Joulaei, M., Mirbolouki, M., \& Bagherzadeh-Valami, H. (2019). Classifying fuzzy flexible measures in data envelopment analysis. Journal of Intelligent \& Fuzzy Systems, 36, 3791-3800. https://doi.org/10.3233/JIFS-18698

Kamei, T. (1997). Risk management. Tokyo: Dobunkan (in Japanese).

Katuwal, R., Suganthan, P. N., \& Zhang, L. (2018). An ensemble of decision trees with random vector functional link networks for multi-class classification. Applied Soft Computing, 70, 1146-1153. https://doi.org/10.1016/j.asoc.2017.09.020

Kim, Y., Choi, T. Y., \& Yan, T. (2011). Structural investigation of supply networks: A social network analysis approach. Journal of Operations Management, 29(3), 194-211. https://doi.org/10.1016/j.jom.2010.11.001

Kim, D. Y. (2014). Understanding supplier structural embeddedness: A social network perspective. Journal of Operations Management, 32(5), 219-231. https://doi.org/10.1016/j.jom.2014.03.005

Kritikos, M. N. (2017). A full ranking methodology in data envelopment analysis based on a set of dummy decision making units. Expert Systems with Applications, 77, 211-225. https://doi.org/10.1016/j.eswa.2017.01.042

Kirkos, E., Spathis, C., \& Manolopoulos, Y. (2007). Data Mining techniques for the detection of fraudulent financial statements. Expert Systems with Applications, 32(4), 995-1003. https://doi.org/10.1016/j.eswa.2006.02.016

Kwon, I. W. G., \& Suh, T. (2005). Trust, commitment and relationships in supply chain management: a path analysis. Supply Chain Management: An International Journal, 10(1), 26-33. https://doi.org/10.1108/13598540510578351

Lambert, D. M., Cooper, M. C., \& Pagh, J. D. (1998). Supply chain management: Implementation issues and research opportunities. The International Journal of Logistics Management, 9(2), 1-20. https://doi.org/10.1108/09574099810805807

Liu, Z., \& Cruz, J. M. (2012). Supply chain networks with corporate financial risks and trade credits under economic uncertainty. International Journal of Production Economics, 137(1), 55-67. https://doi.org/10.1016/j.ijpe.2012.01.012

Loughran, T., \& McDonald, B. (2011). When is a liability not a liability? Textual analysis, dictionaries, and 10-Ks. Journal of Finance, 66(1), 35-65. https://doi.org/10.1111/j.1540-6261.2010.01625.x

Li, F. (2010). The information content of forward-looking statements in corporate filings-A naive Bayesian machine learning approach. Journal of Accounting Research, 48(5), 1049-1102. https://doi.org/10.1111/j.1475-679X.2010.00382.x 
Li, X., Shao, Z., \& Qian, J. (2002). An optimizing method based on autonomous animats: fish-swarm algorithm. Systems Engineering-Theory and Practice, 22(11), 32-38.

Lin, S. J. (2017). Hybrid kernelized fuzzy clustering and multiple attributes decision analysis for corporate risk management. International Journal of Fuzzy Systems, 19, 659-670. https://doi.org/10.1007/s40815-016-0196-7

Lin, S. J., \& Hsu, M. F. (2018). Decision making by extracting soft information from CSR news report. Technological and Economic Development of Economy, 24(4), 1344-1361. https://doi.org/10.3846/tede.2018.3121

Lin, S. J., Chang, T. M., \& Hsu, M. F. (2019). An emerging online business decision making architecture in a dynamic economic environment. Journal of Intelligent \& Fuzzy Systems, 37(2), 1893-1903. https://doi.org/10.3233/JIFS-179251

Lu, W. M., Liu, J. S., Kweh, Q. L., \& Wang, C. W. (2016). Exploring the benchmarks of the Taiwanese investment trust corporations: Management and investment efficiency perspectives. European Journal of Operational Research, 248(2), 607-618. https://doi.org/10.1016/j.ejor.2015.06.065

Lu, W. M., Kweh, Q. L., Nourani, M., \& Huang, F. W. (2016). Evaluating the efficiency of dual-use technology development programs from the R\&D and socio-economic perspectives. Omega, 62, 82-92. https://doi.org/10.1016/j.omega.2015.08.011

Magnusson, C., Arppe, A., Eklund, T., Back, B., Vanharanta, H., \& Visa, A. (2005). The language of quarterly reports as an indicator of change in the company's financial status. Information \& Management, 42(4), 561-574. https://doi.org/10.1016/j.im.2004.02.008

Narasimhan, R., \& Nair, A. (2005). The antecedent role of quality: Information sharing and supply chain proximity on strategic alliance formation and performance. International Journal of Production Economics, 96, 301-313. https://doi.org/10.1016/j.ijpe.2003.06.004

Nosrat, A., Sanei, M., Payan, A., Hosseinzadeh L. F., \& Razavyan, S. (2019). Using credibility theory to evaluate the fuzzy two-stage DEA: sensitivity and stability analysis. Journal of Intelligent \& Fuzzy Systems, 37(4), 5777-5796. https://doi.org/10.3233/JIFS-181519

Parkin, D., \& Hollingsworth, B. (1997). Measuring production efficiency of acute hospitals in Scotland, 1991-94: validity issues in data envelopment analysis. Applied Economics, 29(11), 1425-1433. https://doi.org/10.1080/000368497326255

Pao, Y. H., \& Takefuji, Y. (1992). Functional-link net computing: theory, system architecture, and functionalities. Computer, 25(5), 76-79. https://doi.org/10.1109/2.144401

Pawlak, Z. (1982). Rough sets. International Journal of Information and Computer Sciences, 11(5), 341356. https://doi.org/10.1007/BF01001956

Petersen, M. A. (2004). Information: Hard and soft (Technical report). Northwestern University.

Pan, W. T. (2009). Forecasting classification of operating performance of enterprises by ZSCORE combining ANFIS and genetic algorithm. Neural Computing and Applications, 18, 1005-1011. https://doi.org/10.1007/s00521-009-0243-5

Peteraf, M. A. (1993). The cornerstones of competitive advantage: A resource-based view. Strategic Management Journal, 14(3), 179-191. https://doi.org/10.1002/smj.4250140303

Ross, A., \& Droge, C. (2002). An integrated benchmarking approach to distribution center performance using DEA modeling, Journal of Operations Management, 20, 19-32.

https://doi.org/10.1016/S0272-6963(01)00087-0

Ramanathan, R., Ramanathan, U., \& Bentley, Y. (2018). The debate on flexibility of environmental regulations, innovation capabilities and financial performance - A novel use of DEA. Omega, 75, 131-138. https://doi.org/10.1016/j.omega.2017.02.006

Radojicic, M., Savic, G., \& Jeremic, V. (2018). Measuring the efficiency of banks: The bootstrapped I-distance GAR DEA approach. Technological and Economic Development of Economy, 24(4), 15811605. https://doi.org/10.3846/tede.2018.3699 
Sagarra, M., Mar-Molinero, C., \& Agasisti, T. (2017). Exploring the efficiency of Mexican universities: Integrating Data Envelopment Analysis and Multidimensional Scaling. Omega, 67, 123-133. https://doi.org/10.1016/j.omega.2016.04.006

Scardapane, S., Comminiello, D., Scarpiniti, M., \& Uncini, A. (2016). A semi-supervised random vector functional-link network based on the transductive framework. Information Sciences, 364-365, 156-166. https://doi.org/10.1016/j.ins.2015.07.060

Schmidt, W. F., Kraaijveld, M. A., \& Duin, R. P. W. (1992). Feedforward neural networks with random weights. In 11th IAPR International Conference on Pattern Recognition (pp. 1-4).

Scardapane, S., Wang, D., Panella, M., \& Uncini, A. (2015). Distributed learning for Random Vector Functional-Link networks. Information Sciences, 301, 271-284. https://doi.org/10.1016/j.ins.2015.01.007

Scalzer, R. S., Rodrigues, A., Macedo, M., Á. da S., \& Wanke, P. (2018). Insolvency of Brazilian electricity distributors: a DEA bootstrap approach. Technological and Economic Development of Economy, 24(2), 718-738. https://doi.org/10.3846/20294913.2017.1318312

Shie, F. S., Chen, M. Y., \& Liu, Y. S. (2012). Prediction of corporate financial distress: an application of the America banking industry. Neural Computing and Applications, 21(7), 1687-1696. https://doi.org/10.1007/s00521-011-0765-5

Tan, K. C., Lyman, S. B., \& Wisner, J. D. (2002). Supply chain management: A strategic perspective. International Journal of Operations \& Production Management, 22(6), 614-631. https://doi.org/10.1108/01443570210427659

Tajvidi, R., \& Karami, A. (2017). The effect of social media on firm performance. Computers in Human Behavior (in press). https://doi.org/10.1016/j.chb.2017.09.026

Uysal, A. K., \& Gunal, S. (2012). A novel probabilistic feature selection method for text classification. Knowledge-Based Systems, 36, 226-235. https://doi.org/10.1016/j.knosys.2012.06.005

Wang, W. K., Lu, W. M., Kweh, Q. L., \& Cheng, I. T. (2014). Does intellectual capital matter? Assessing the performance of CPA firms based on additive efficiency decomposition DEA. Knowledge-Based Systems, 65, 38-49. https://doi.org/10.1016/j.knosys.2014.04.004

Walter, A., Auer, M., \& Ritter, T. (2006). The impact of network capabilities and entrepreneurial orientation on university spin-off performance. Journal of Business Venturing, 21(4), 541-567. https://doi.org/10.1016/j.jbusvent.2005.02.005

Wernerfelt, B. (1984). A resource-based view of the firm. Strategic Management Journal, 5(2), 171-180. https://doi.org/10.1002/smj.4250050207

West, D., Dellana, S., \& Qian, J. (2005). Neural network ensemble strategies for financial decision applications. Computers \& Operations Research, 32(10), 2543-2559. https://doi.org/10.1016/j.cor.2004.03.017

Wu, I. L., \& Chiu, M. L. (2018). Examining supply chain collaboration with determinants and performance impact: Social capital, justice, and technology use perspectives. International Journal of Information Management, 39, 5-19. https://doi.org/10.1016/j.ijinfomgt.2017.11.004

Zhang, X., Shi, J., Wang, D., \& Fang, B. (2018). Exploiting investors social network for stock prediction in China's market. Journal of Computational Science, 28, 294-303. https://doi.org/10.1016/j.jocs.2017.10.013

Zhang, L., \& Suganthan, P. N. (2016). A comprehensive evaluation of random vector functional link networks. Information Sciences, 367-368, 1094-1105. https://doi.org/10.1016/j.ins.2015.09.025

Zheng, J., Wang, Y. M., Chen, L., \& Zhang, K. (2019). A new case retrieval method based on double frontiers data envelopment analysis. Journal of Intelligent \& Fuzzy Systems, 36, 199-211. https://doi.org/10.3233/JIFS-181106 